\title{
Manganese dioxide as a potential cathodic reactant in corrosion of stainless steels
}

\author{
B.H. Olesen ${ }^{\mathrm{a}, \mathrm{b}}$, R. Avci ${ }^{\mathrm{c}}$, Z. Lewandowski ${ }^{\mathrm{b}, *}$

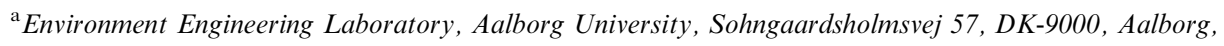 \\ Denmark \\ ${ }^{\mathrm{b}}$ Center for Biofilm Engineering, EPS 366, Montana State University, Bozeman, MT 59717-3980, USA \\ ${ }^{\mathrm{c}}$ Image and Chemical Analysis Laboratory, Department of Physics, EPS 259, Montana State University, \\ Bozeman, MT 59717-0350, USA
}

Received 3 April 1998; accepted 22 April 1999

\begin{abstract}
Biofilms of Leptothrix discophora SP-6, grown on 316L stainless steel (SS), ennobled the open circuit potential to $410 \mathrm{mV}_{\mathrm{SCE}}$. X-ray Photoelectron Spectroscopy (XPS) identified $\mathrm{MnO}_{2}$ within these biofilms. Field exposed SS showed similar ennoblement after 30 days. XPS analysis of these samples revealed a mixture of different manganese minerals. Electrochemical reduction of $\mathrm{MnO}_{2}$ was studied using electroplated SS. Plated $\mathrm{MnO}_{2}$ was reduced amperometrically. The process was interrupted at different reduction stages. XPS analysis of remaining oxides showed that $\mathrm{MnO}_{2}$ was reduced through $\mathrm{MnOOH}$ to $\mathrm{Mn}^{2+}$. We conclude that biomineralized $\mathrm{MnO}_{2}$ may increase corrosion rates by serving as a cathodic reactant. (C) 2000 Elsevier Science Ltd. All rights reserved.
\end{abstract}

\section{Introduction}

Microbial colonization of metals can influence the rate and the mechanisms of electrochemical reactions. An example of such behavior is ennoblement of passive metals, a process during which the Open Circuit Potential (OCP) of microbially colonized metals becomes more positive (noble). An increase in cathodic current

\footnotetext{
* Corresponding author. Tel.: + 1-406-994-5915; fax: + 1-406-994-6098.

E-mail address: zl@erc.montana.edu (Z. Lewandowski).
} 
density, during cathodic polarization, is usually associated with the increase in OCP.

Mollica and Trevis [1] discovered that biofilm formation on three types of stainless steel changed their electrochemical behavior in two ways: (1) OCP was shifted in positive direction from initial values around +30 to $+450 \mathrm{mV}$ versus the Saturated Calomel Electrode (SCE), and (2) the cathodic current, during cathodic polarization, increased from $10^{-9}$ to $10^{-7} \mathrm{~A} / \mathrm{cm}^{2}$. Their paper was one of the first describing microbially enhanced ennoblement of stainless steels. In a similar experiment Johnsen and Bardal [2] polarized six different stainless steels at several different levels from -300 and $-950 \mathrm{mV}_{\mathrm{SCE}}$ in flowing sea water, and found that the cathodic current increased from about $10^{-7}$ to $10^{-4} \mathrm{~A} / \mathrm{cm}^{2}$ during exposure. Dexter and Gao [3] showed a similar effect on 316 stainless steel exposed to a marine biofilm. They noticed that the increase in OCP was consistently was associated with an increase in the cathodic current. Motoda et al. [4] exposed 18 types of stainless steel and titanium to sea water. OCP of the samples gradually increased from $-100 \mathrm{mV}$ and stabilized at $+400 \mathrm{mV}_{\mathrm{SCE}}$ within 10 days. Titanium samples in their experiment reached similar potentials after 3040 days of exposure. Also in their case the increased OCP was associated with an increased cathodic current. During the exposure, a brownish slime layer, mainly composed of sea diatoms, was formed on the surface. Samples remained ennobled after removal of the slime layer, but the removal of a thin organic layer on the surface shifted OCP to pre-exposure values. Eashwar et al. [5] exposed titanium to natural seawater while setting the illumination of the samples at three levels: dark, moderate light and strong light intensity. Only the samples illuminated by moderate light intensity were ennobled. The biofilm covering the samples consisted of bacteria and diatoms. Similar observations of passive metal ennoblement have been reported by Scotto et al. [6], Holthe et al. [7], Little et al. [8] and Eashwar and Maruthamuthu [9].

A wide variety of theoretical explanations of bacterial ennoblement of passive metals were offered. It is uniformly believed that microbial colonization is responsible for the ennoblement $[1,2,6]$. The overall effect has been prescribed to microbial production of extracellular substances [1], organo metallic complexes [2] or specific enzymes [6]. Some workers have explained the ennoblement shift through microbially modified acidification near the metal surface $[3,10]$, combined effect of acidification and production of hydrogen peroxide near the surface [11], production of a "thin organic film" on the metal surface [4] or production of passivating siderophores [9].

Recently some researchers have noticed a connection between microbial deposition of iron and manganese oxides/hydroxides and passive metal ennoblement [12-16]. Linhardt [12,13] investigated pitting corrosion of turbine runner blades (CrNil34) in a hydroelectric power plant in the Netherlands. The chloride concentration in the water was in the range $20-170 \mathrm{mg} / \mathrm{l}$, which was not enough to stimulate pitting corrosion of the used material. SEM/EDAX and Xray diffraction analysis of deposits from the corroded runner blades indicated significant amounts of manganese oxyhydroxide (approximately $25 \% \mathrm{w} / \mathrm{w}$ ) and 
manganese dioxide (approximately $8 \% \mathrm{w} / \mathrm{w}$ ). To describe the roles of the deposits in observed pitting corrosion, a sample of the deposits from the runner blades was pressed into a pellet, connected to a reference electrode, and immersed in water. A potential of $+570 \mathrm{mV}$ against a hydrogen electrode was measured at $\mathrm{pH} 7.5$, $20^{\circ} \mathrm{C}$, and a bulk water $\mathrm{Mn}^{2+}$ concentration of $0.1 \mathrm{mg} / 1$. Linhardt concluded that the presence of manganese dioxide on the stainless steel surface was responsible for the increase of the OCP as described by reaction (1).

$$
\mathrm{MnO}_{2}+4 \mathrm{H}^{+}+2 \mathrm{e}^{-} \rightarrow \mathrm{Mn}^{2+}+2 \mathrm{H}_{2} \mathrm{O} ; \quad E^{0},=+550 \mathrm{mV}_{\mathrm{SCE}}
$$

In our laboratory, Dickinson et al. [14,15] found that 316L stainless steel exposed to a fresh water creek gradually increased the OCP from $-150 \mathrm{mV}$ to $+350 \mathrm{mV}_{\mathrm{SCE}}$ during 30 days. Furthermore, polarization tests showed a 2-3 fold increase in cathodic current density, quite consistent with the known cases of ennoblement in sea water. After exposure, the corrosion coupons were covered with a large number of ring shaped deposits containing manganese oxides. Dickinson et al. also demonstrated the same electrochemical behavior, when approximately $20 \%$ of the stainless steel surface was covered with a thin film of hydrous manganese dioxide in an abiotic experiment. To demonstrate that the effect was caused by microbial action, Dickinson et al. [16] exposed 316L stainless steel to a pure culture of Manganese Oxidizing Bacteria (MOB), Leptothrix discophora SP-6, in a mineral-salt-pyruvate-vitamin medium containing divalent manganese. Similar biologically induced electrochemical changes were observed under these controlled laboratory conditions. Consequently, Dickinson et al. concluded that the observed changes in electrochemical behavior of stainless steel were caused by microbial deposition of manganese oxides on the stainless steel surface and proposed the following reaction as responsible for the observed electrochemical behavior $[14,15]$ :

$$
\mathrm{MnO}_{2}+\mathrm{H}_{2} \mathrm{O}+\mathrm{e}^{-} \rightarrow \mathrm{MnOOH}+\mathrm{OH}^{-} ; \quad E^{0},=335 \mathrm{mV}_{\mathrm{SCE}}(\mathrm{pH} 8.0)
$$

Both Linhardt [12,13] and Dickinson et al. [14-16] demonstrated that the deposition of manganese oxides on stainless steels changed the electrochemical behavior. However, the authors disagreed on an important issue: the stoichiometry of the electrochemical reaction responsible for the observed effects. From their work the composition of the microbially deposited manganese oxides was not clearly defined. In fact, little is known about the nature of microbially deposited manganese. Adams and Ghiorse [17] analyzed manganese deposits by the manganese oxidizing bacterium L. discophora SS-1 and found that the oxidation state of manganese was between 3.32 and 3.62, and varied with the oxide age.

This paper attempts to answer two questions: (1) what is the mineralogy of the biologically deposited manganese oxides and (2) what are the kinetics of electrochemical reduction of the manganese oxides biologically deposited on stainless steel surfaces? To answer the first question, we grew pure culture biofilms of $\mathrm{MOB}$ on $316 \mathrm{~L}$ stainless steel corrosion coupons under laboratory conditions. 
The deposits were analyzed by X-ray Photoelectron Spectroscopy (XPS). Similar analyses were performed on coupons ennobled during exposure to a fresh water creek. The second question was addressed by using coupons electroplated with a thin layer of manganese oxide. The deposited oxide was slowly reduced by passing a small cathodic current across the metal/deposit/water interfaces. Analyses of the deposits before and after the electrochemical reduction provided information about the kinetics of the manganese oxide reduction. The composition of the deposits was determined by comparing the XPS spectra of the deposits with the XPS spectra of different manganese minerals of known composition.

\section{Materials and methods}

316L stainless steel corrosion coupons $1.6 \mathrm{~cm}$ diameter (Metal Samples Inc., Munford, AL) were sonicated in 95\% ethanol, air dried and mounted in holders made of polycarbonate (for laboratory use) or PVC (for field exposure) using a slow hardening epoxy (Buehler Epoxide). Table 1 shows the composition of the stainless steel samples as provided by the vendor. Excess epoxy was removed using 320 grit sandpaper and the surface was polished using 600-grit sandpaper. The coupons were sonicated in distilled water, then in 95\% ethanol, and finally air dried. Electrical connections, to monitor OCP of the coupons, were made by attaching adhesive copper tape to the back of the coupons inside the holders. Prior to use, the coupons were left in contact with atmospheric air for $24 \mathrm{~h}$, during which a protective surface layer of metal oxides formed. Coupons for biological experiments were sterilized by soaking in $95 \%$ ethanol for one minute, followed by exposure to UV-light for $12 \mathrm{~h}$.

\subsection{Laboratory ennobled samples}

Manganese oxidizing bacteria, Leptothrix discophora SP-6 [18], were obtained (freeze dried) from American Type Culture Collection (ATCC no. 51168). After receipt, we grew the organisms in mineral-salt-pyruvate-vitamin (MSPV) medium (ATCC no. 1917). Subcultures were concentrated by centrifugation, resuspended in MSPV medium containing $10 \%$ glycerol, and preserved by freezing at $-70^{\circ} \mathrm{C}$ [19]. Prior to each experiment we thawed a frozen culture and incubated it for $48 \mathrm{~h}$ in $5 \mathrm{ml} \mathrm{MSPV} \mathrm{medium;} 1 \mathrm{ml}$ of this culture was transferred to $100 \mathrm{ml}$ MSPV medium and incubated for $48 \mathrm{~h} ; 5 \mathrm{ml}$ of the second culture was used to inoculate

Table 1

Elemental composition (wt.\%) of 316L stainless steel corrosion coupons as provided by vendor (Metal Samples Inc., Munford, AL)

\begin{tabular}{llllllllll}
\hline $\mathrm{Fe}$ & $\mathrm{Cr}$ & $\mathrm{Ni}$ & $\mathrm{Mo}$ & $\mathrm{Mn}$ & $\mathrm{Si}$ & $\mathrm{P}$ & $\mathrm{N}$ & $\mathrm{C}$ & $\mathrm{S}$ \\
\hline Bal. & 16.19 & 10.19 & 2.10 & 1.71 & 0.39 & 0.034 & 0.03 & 0.017 & 0.001 \\
\hline
\end{tabular}


$500 \mathrm{ml}$ MSPV medium containing $200 \mu \mathrm{M} \mathrm{Mn}(\mathrm{II})$ [16] as $\mathrm{MnSO}_{4}$ in the experimental batch reactor.

For laboratory exposure of stainless steel samples to L. discophora SP-6, we placed a set of eight coupons in a 11 polycarbonate container with $500 \mathrm{ml}$ MSPV medium containing $200 \mu \mathrm{M} \mathrm{Mn}(\mathrm{II})$. The coupons were mounted face down through holes in the lid. OCPs were measured every hour against an SCE. Electrical connection between the reactor and the SCE was made through a saltbridge containing $1 \%$ agar and $1 \mathrm{mM} \mathrm{Na}_{2} \mathrm{SO}_{4}$. Potentials were measured for $48 \mathrm{~h}$ prior to inoculating to assure stable conditions.

\subsection{Field ennobled samples}

For field exposure we placed a set of $316 \mathrm{~L}$ stainless steel corrosion coupons in Roskie Creek, a fresh water creek in Bozeman, Montana. This particular site has previously been classified as a clean stream [14]. The coupons were mounted in a PVC plate $(10 \times 50 \mathrm{~cm})$ and placed face down approximately $10 \mathrm{~cm}$ above the sediment. Electrical connections were extended $30 \mathrm{~cm}$ above the surface and sealed in a waterproof bag between measurements. During 40 days of exposure we checked the set-up frequently to ensure free flowing water under the coupons and measured OCPs weekly against SCE. During the time of exposure we determined the following parameters: $\mathrm{pH} 6.8-7.2$, temperature $11-18^{\circ} \mathrm{C}$, conductivity $150 \mu \mathrm{S}$, $\mathrm{Mn}^{2+} 60-80 \mu \mathrm{g} / \mathrm{l}, \mathrm{Fe} 300 \mu \mathrm{g} / \mathrm{l}$, dissolved oxygen $8-9 \mathrm{mg} / \mathrm{l}$.

\subsection{Electrochemical reduction of $\mathrm{MnO}_{2}$}

For the kinetic study of manganese reduction, we galvanostatically plated manganese dioxide on stainless steel corrosion coupons in an aqueous electrolyte containing $0.1 \mathrm{M} \mathrm{Na}_{2} \mathrm{SO}_{4}$ and $5 \mathrm{mM} \mathrm{MnSO}_{4}$ at $\mathrm{pH} 6.5$. A charge of $30 \mathrm{mC} / \mathrm{cm}^{2}$ was transferred at $0.1 \mathrm{~mA} / \mathrm{cm}^{2}$, corresponding to $13.5 \mu \mathrm{g} / \mathrm{cm}^{2} \mathrm{MnO}_{2}$ or a $270 \mathrm{~nm}$ thick layer of solid $\mathrm{MnO}_{2}$. During the time of plating, the potential of the stainless steel samples reached about $900 \mathrm{mV}$, which could have been outside the range of water stability, depending upon the $\mathrm{pH}$ near the surface. Subsequently, the coupons were immersed in $0.1 \mathrm{M} \mathrm{Na}_{2} \mathrm{SO}_{4}$ at $\mathrm{pH} 6.5$ and the manganese oxide was reduced amperometrically. We used a three electrode set-up consisting of the stainless steel coupon as the working electrode, a SCE as a reference, and a $2 \mathrm{~cm}^{2}$ graphite disc as the auxiliary electrode. The chronopotentiometric reduction was controlled by a potentiostat/galvanostat model 273A with a matching software, version 4.23 from EG and G Princeton Applied Research. Current density was set to $2 \mu \mathrm{A} / \mathrm{cm}^{2}$ and the resulting potential was monitored. Five coupons were reduced for $0.5,1.5,2.5,3$ and $3.5 \mathrm{~h}$.

During electroplating we deposited identical amounts, $30 \mathrm{mC} / \mathrm{cm}^{2}$, of manganese dioxide on each of five coupons. However, during the following electrochemical reduction we were only able to recover about $22 \mathrm{mC} / \mathrm{cm}^{2}$ before the potential curve dropped. Hypothetically, this could have been an effect of oxygen evolution during the electroplating of manganese dioxide on the samples. 
The potentials of the stainless steel samples were stable at about $900 \mathrm{mV}$ through the time of plating. Since the potential of the steel sample remained within the range of water stability during the electrochemical reduction, the $22 \mathrm{mC} / \mathrm{cm}^{2}$ of manganese dioxide is therefore a better value for the amount of plated material. Repeated reduction measurements were accurate enough to predict when the plateau would drop to a lower level as a result of depleting the manganese dioxide. This gave us a high degree of control over the experiment and made it possible, using several coupons, to interrupt the oxide reduction process at several points along the potential curve to collect samples for XPS analysis.

Following each reduction experiment, the concentration of dissolved manganese in the electrolyte was measured by the formaldoxine method [20]. An amount, $0.5 \mathrm{ml}$, of each sample and standard was treated with $1.5 \mathrm{ml}$ ammoniaformaldoxine reagent. Absorbance was measured after 30 min at $450 \mathrm{~nm}$. Volumetric concentrations of manganese were converted to equivalent surface concentrations accounting for the electrolyte volume and the surface area of the sample.

\subsection{X-ray photoelectron spectroscopy}

Surface analsyses were performed by small spot X-ray Photoelectron Spectroscopy [21] (XPS) using an electron spectrometer, model PHI $5600 \mathrm{ci}$, located in the Image and Chemical Analysis Laboratory (ICAL), Department of Physics, MSU, Bozeman, MT. Pass energies of 93.9 and $58.7 \mathrm{eV}$ (corresponding to 1.2 and $0.97 \mathrm{eV} \mathrm{FWHM} \mathrm{of} \mathrm{the} \mathrm{Ag3} \mathrm{d} \mathrm{peak} \mathrm{respectively)} \mathrm{were} \mathrm{used} \mathrm{for} \mathrm{full} \mathrm{and}$ partial scans with lens aperture no. 4 analyzing an area of $800 \mu \mathrm{m}$ in diameter.

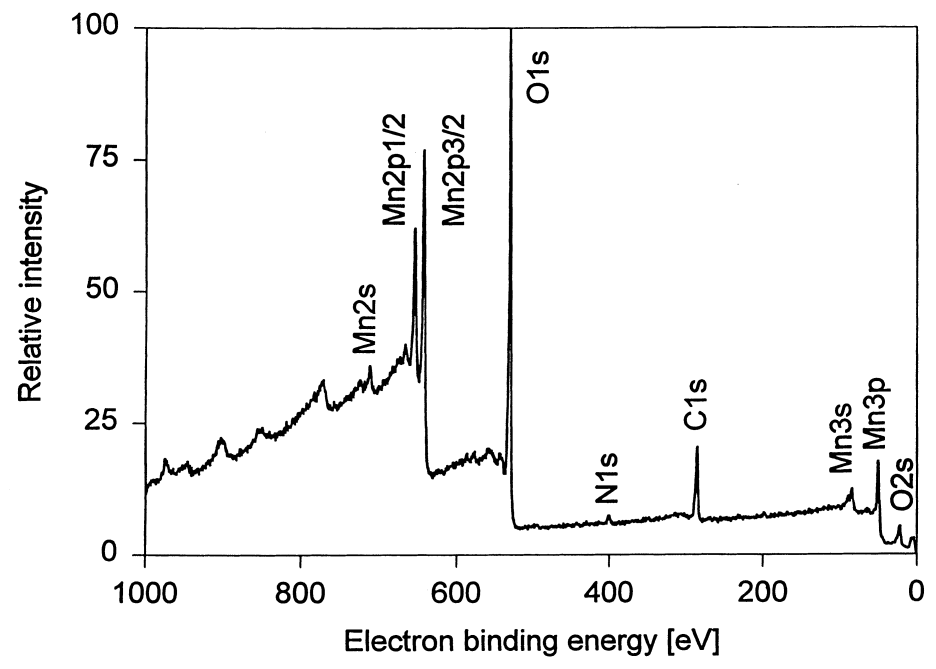

Fig. 1. XPS survey spectrum of $316 \mathrm{~L}$ stainless steel electroplated with a $270 \mathrm{~nm}$ thick layer of manganese dioxide. 
XPS uses monochromatized Al-K $\alpha$ X-rays to eject photoelectrons from the surface and the near surface regions $(0-50 \AA)$. These photoelectrons include those emitted from core and valence levels of atoms and molecules. Because the corelevel energy states, particularly those of shallow levels (i.e. Mn3p), are perturbed by the local bonding and charge states of species, small shifts in the binding energies (chemical shifts) provides a picture of the chemical environment of the elements and their abundance. XPS has previously been used to study manganese oxide systems [22,23] and to perform surface analysis of different metals [24-26].

Fig. 1 shows a survey spectrum $(0-1000 \mathrm{eV})$ obtained from $316 \mathrm{~L}$ SS electroplated with manganese dioxide. Binding energies and the core level profiles were obtained by choosing an appropriate binding energy window, such as 43 to $63 \mathrm{eV}$ for Mn3p. The position of the peak maximum determines the binding energy of the Mn3p, which in turn is related to the ionicity. Reference spectra of different manganese containing compounds were collected to determine the ionicity of the $\mathrm{Mn}$ species in the matrix.

We used six manganese compounds as standards. Five of them were commercial products from Aldrich Chemical Company, Inc: $\mathrm{MnO}(99 \%), \mathrm{Mn}_{2} \mathrm{O}_{3}(97 \%)$, $\mathrm{Mn}_{3} \mathrm{O}_{4}(99 \%)$, Mn metal (99.98\%) and $\mathrm{MnO}_{2}$ (99\%). The sixth standard, manganese oxyhydroxide, was prepared by oxidation of manganese sulfate [27,28]. First, $20.4 \mathrm{ml} 30 \% \mathrm{H}_{2} \mathrm{O}_{2}$ was added to $110.06 \mathrm{M} \mathrm{MnSO}_{4}$. Then, while stirring vigorously, $300 \mathrm{ml} 0.2 \mathrm{M} \mathrm{NH}_{4} \mathrm{OH}$ was added, and the solution was heated to $95^{\circ} \mathrm{C}$ for $6 \mathrm{~h}$. The mixture was filtered through a $0.4 \mu \mathrm{m}$ nylon filter, and the filtrate was washed several times with hot water prior to drying in a desiccator for two days at room temperature.

Manganese mineral standards for XPS analysis were prepared by pressing the respective powdered compounds into a piece of soft indium foil (Alfa ÆSAR) between two microscope slides. Spectra of samples, prepared this way, included a small peak for indium. The presence of indium, however, did not interfere with any peaks of importance to this study. Solid manganese metal, used as a standard, was ground with a diamond file immediately before the analysis to remove oxidized surface layers. After positioning in the ultra high vacuum chamber, the manganese metal sample was sputtered using an argon beam to remove the rest of the oxide film.

Before XPS analysis, corrosion coupons were rinsed with distilled water to remove soluble components, air dried, and mechanically removed from their holders. Any epoxy left on the coupon was removed with a razor blade. Coupons were kept separately in airtight containers for up to $24 \mathrm{~h}$ prior to analysis. Prior to analysis of manganese deposits within laboratory grown biofilms, most of the biofilm was gently removed using distilled water and a cotton swab. In order to get enough material for analysis of manganese minerals on field exposed coupons; deposits were scraped from several samples using a razor blade. The deposits were then mounted as described for powdered standards.

Except for the sputtered manganese metal, all spectra showed a small amount of carbon originating from atmospheric contamination. The position of the carbon $\mathrm{C} 1 \mathrm{~s}$ peak is not affected by the chemical composition and structure of the 
sample, and remains at $284.5 \mathrm{eV}^{21}$. We used the $\mathrm{C} 1 \mathrm{~s}$ peak position as a fix-point for the XPS spectrum. In some cases it was necessary to use charge neutralization of the surface, in order to obtain the right position of the $\mathrm{C} 1 \mathrm{~s}$ peak. Manganese metal was analyzed to compare observed binding energies with standard values [21]. Table 2 shows observed and standard values for the $2 p$ and $3 p$ binding energies of manganese metal.

The relation between the binding energy of the manganese minerals and their chemical composition was most significant for the Mn3p peak. This was expected, as the outer shell electrons are more sensitive to interactions of the Mn valence electrons, involved in molecular bonds, thus $\mathrm{Mn} 3 \mathrm{p}$ is more affected by the molecular composition than, say, Mn2p.

\section{Results}

Our experiments showed that the binding energies of the Mn3p peak, as they depend on the local charge configuration of Mn ions, increases with the valence of the manganese atom (Table 3). Due to similar configurations of the manganese atom, the $\mathrm{Mn} 3 \mathrm{p}$ binding energies for $\mathrm{MnOOH}$ and $\mathrm{MnO}_{2}$ are very close, despite the difference in valence. The differences in positions and widths of the overlapping peaks, however, were significant, which enabled deconvolution and differentiation between the two compounds. Peak fitting software accompanying the PHI spectrometer furthermore enabled deconvolution of overlapping peaks of different manganese compounds using the values for peak position, width, etc. from the standard compounds.

\subsection{Laboratory ennobled samples}

Eight coupons of $316 \mathrm{~L}$ stainless steel exposed to L. discophora SP-6 under laboratory conditions ennobled within 3-5 days following inoculation (Fig. 2). The OCP reached a steady value of $+410 \pm 10 \mathrm{mV}_{\mathrm{SCE}}$ within 11 days following inoculation. Fig. 3 shows XPS spectra of the deposits and pure manganese dioxide, $\mathrm{MnO}_{2}$. The $\mathrm{Mn} 3 \mathrm{p}$ peak for the biomineralized manganese is located at 49.6-50.0 eV (range of all analyzed samples), whereas the two neighboring manganese standards, manganese dioxide and manganese oxyhydroxide (not shown), have peaks at 49.55 and $49.13 \mathrm{eV}$ (Table 3). The rest of the manganese standards have energy peaks between 48.6 and $47.7 \mathrm{eV}$ (Table 3). The biological

Table 2

Standard and observed binding energies $[\mathrm{eV}]$ for the $2 \mathrm{p}$ and $3 p$ levels of manganese metal

\begin{tabular}{llll}
\hline Electron orbital & $2 \mathrm{p} 1 / 2$ & $2 \mathrm{p} 3 / 2$ & $3 \mathrm{p}$ \\
\hline Standard Binding energy [21] & 650 & 639 & 48 \\
Observed Binding energy & 650.5 & 639.4 & 47.8 \\
\hline
\end{tabular}


Table 3

Position and width parameters for the Mn3p orbital peak obtained from XPS spectra of different manganese-containing minerals

\begin{tabular}{lcccrcc}
\hline Mineral & $\mathrm{MnO}_{2}$ & $\mathrm{MnOOH}$ & $\mathrm{Mn}_{2} \mathrm{O}_{3}$ & $\mathrm{Mn}_{3} \mathrm{O}_{4}$ & $\mathrm{MnO}$ & Mn metal \\
\hline Valence & 4 & 3 & 3 & 2.67 & 2 & 0 \\
Position [eV] & 49.55 & 49.13 & 48.65 & 48.13 & 48.02 & 47.37 \\
Width [eV] & 2.02 & 1.92 & 1.69 & 1.82 & 1.80 & 1.41 \\
\hline
\end{tabular}

sample includes traces of iron and chromium originating from the underlying stainless steel. The energy curve for the biomineralized manganese is close to the one for manganese dioxide and the width of the two curves are equal, thus we conclude that the biologically deposited mineral was manganese dioxide.

\subsection{Field ennobled samples}

Coupons exposed to creek water for forty days developed similar OCP as the samples exposed to pure culture $L$. discophora SP-6 under laboratory conditions. XPS spectra indicated presence of manganese but the signals were too weak and noisy to identify the mineral composition. However, scraping the deposit off the surface and mounting it on indium foil (as the powdered standards) improved the signal to noise ratio. Fig. 4 shows a spectrum obtained from one such sample along with the two nearest standard spectra. For different field exposed samples we determined Mn3p positions within the range 48.50-48.55 eV. The peak widths

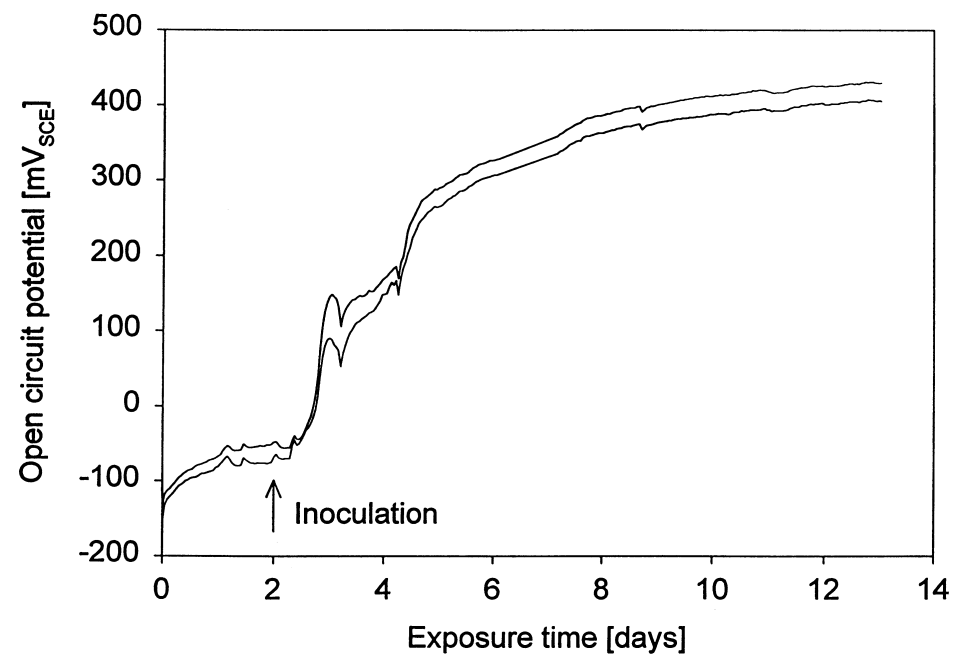

Fig. 2. Open circuit potentials obtained during ennoblement of 316L stainless steel by L. discophora SP6. Area between curves indicates $95 \%$ confidence interval based on eight samples. 


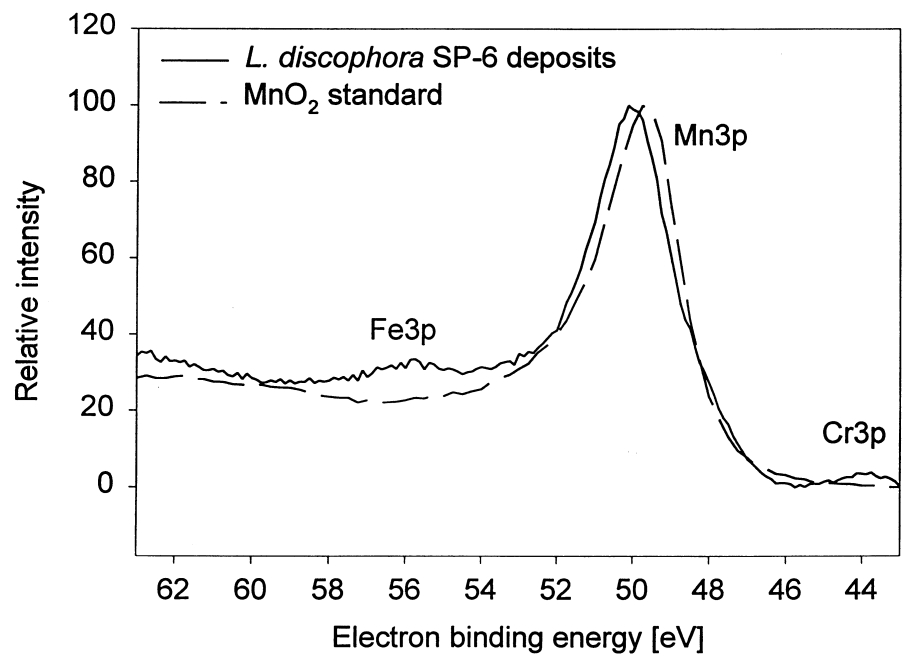

Fig. 3. XPS spectra of a 316L stainless steel coupon exposed to L. discophora SP-6 compared to that of the manganese dioxide standard. The spectra have been scaled arbitrarily so the height of the Mn3p peaks equals 100 .

were consistently $3.6 \mathrm{eV}$. Since neither of the standards have such wide peaks, we concluded that there were two or more manganese minerals with different oxidation states present within the deposits. Comparison with the standards

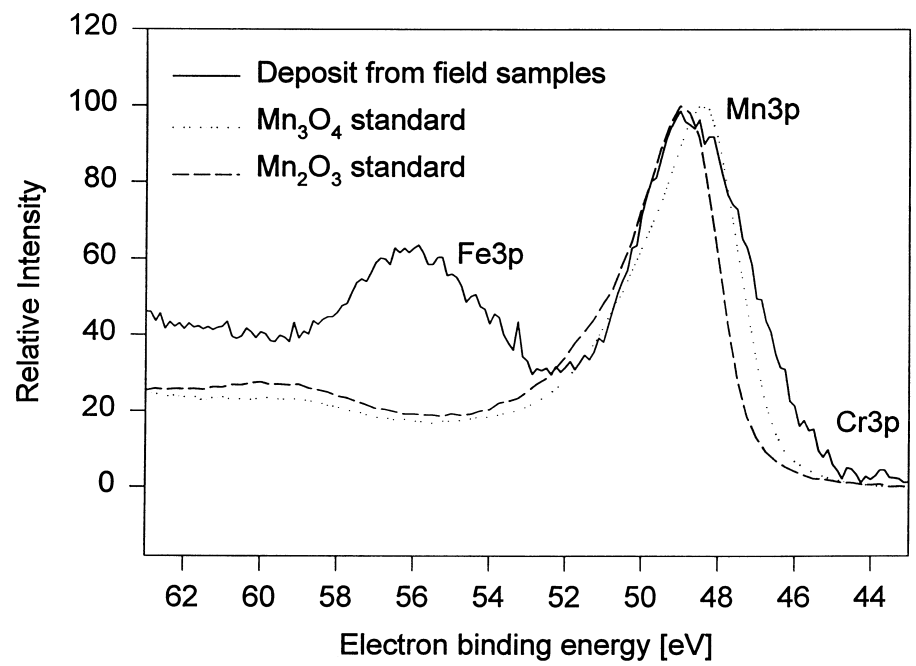

Fig. 4. XPS spectra of manganese rich deposits scraped from a 316L stainless steel coupon exposed in Roskie Creek compared to those of the $\mathrm{Mn}_{2} \mathrm{O}_{3}$ and $\mathrm{Mn}_{3} \mathrm{O}_{4}$ standards. The spectra have been scaled arbitrarily so the height of the Mn3p peaks equals 100 . 
suggested the manganese minerals to be a mixture of $\mathrm{Mn}_{2} \mathrm{O}_{3}$ (peak positioned at 48.65) and $\mathrm{Mn}_{3} \mathrm{O}_{4}$ (peak positioned at $48.13 \mathrm{eV}$ ). Peak fitting the field sample spectra with the two standards showed that manganese minerals with both lower and higher oxidation states also were present.

\subsection{Electrochemical reduction of $\mathrm{MnO}_{2}$}

XPS spectra of electro deposited manganese were similar to those of the $\mathrm{MnO}_{2}$ standard regarding peak position, width, etc. OCP of the plated coupons measured in $1 \mathrm{mM} \mathrm{MnSO} 4$ at $\mathrm{pH} 6.5$ were between +550 and $600 \mathrm{mV}_{\mathrm{SCE}}$. The potential curves obtained during the oxide reduction (Fig. 5) shows that the potential reached a steady plateau shortly after the experiment was initiated, indicating that all reactants in the reaction were abundant. Analysis of dissolved manganese in the electrolyte showed, that manganese was progressively removed from the surface during reduction (Table 4).

We collected the coupons after passing charges of respectively 3.6, 11.2, 18, 21.6, and $25.2 \mathrm{mC} / \mathrm{cm}^{2}$ (Fig. 5). Fig. 6 shows XPS spectra obtained from four of the five reduced coupons, corresponding to the first four squares in Fig. 5. The fifth sample collected after the oxide was depleted, did not show any presence of manganese.

\section{Discussion}

Theoretical behavior of an isolated system containing $1 \mathrm{mM}$ manganese is

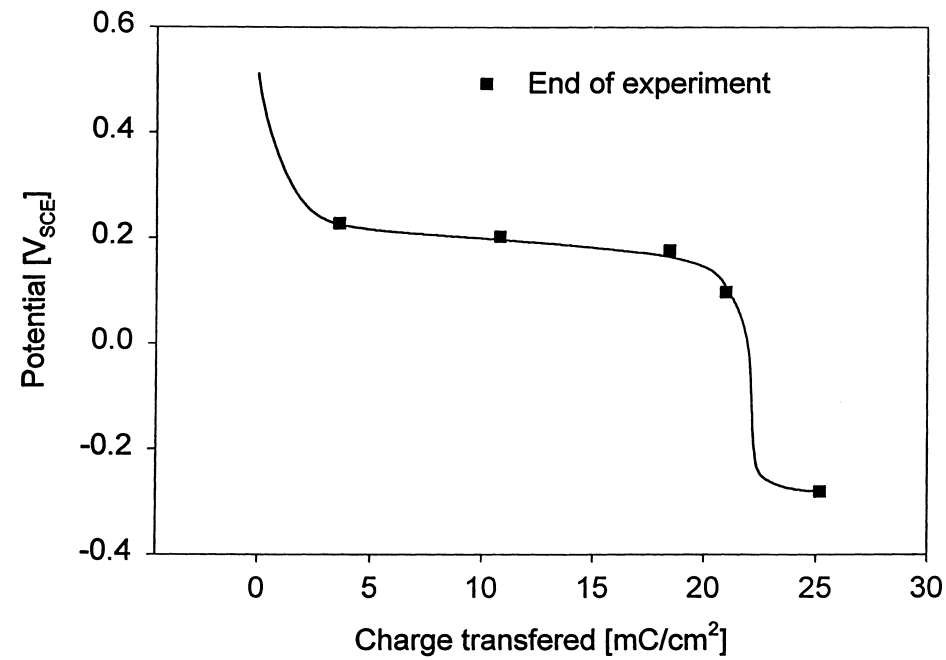

Fig. 5. Potential curves obtained during electrochemical reduction of, $\mathrm{MnO}_{2}$ covered, $316 \mathrm{~L}$ stainless steel coupons. Squares indicate the points where experiments were stopped for XPS analysis. 
Table 4

Amount of manganese lost from the coupon surface during electrochemical reduction determined by analyses of dissolved manganese in the electrolyte

$\begin{array}{llcccc}\text { Charge transferred }\left[\mathrm{mC} / \mathrm{cm}_{2}\right] & 3.6 & 11.2 & 18.0 & 21.6 & 25.2 \\ \text { Manganese removed }\left[\mu \mathrm{g} / \mathrm{cm}_{2}\right] & 2.14 & 5.13 & 8.32 & 9.73 & 12.08\end{array}$

illustrated by a predominance diagram in Fig. 7. The diagram was constructed based upon data collected by Bard et al. [29] (Table 5), and assumes that precipitated compounds are in thermodynamic equilibrium with dissolved manganese.

The concentration of dissolved carbon dioxide, $\mathrm{H}_{2} \mathrm{CO}_{3}$, based on the solubility at $25^{\circ} \mathrm{C}$ was calculated to $1 \times 10^{-5} \mathrm{~mol} / \mathrm{l}$. The predominance diagram shows potential versus $\mathrm{SCE}$ and $\mathrm{p} \epsilon$ against $\mathrm{pH}$, where $\mathrm{p}^{0}=-\Delta G^{0} / 2.3 n \mathrm{RT}$ and $\mathrm{p} \epsilon=-\Delta G / 2.3 n \mathrm{RT}$.

OCP of our manganese-plated stainless steel measured in $1 \mathrm{mM} \mathrm{Mn}$ at varying $\mathrm{pH}$ (indicated as filled squares in Fig. 7) is consistent with the interface between $\gamma \mathrm{MnO}_{2}$ and $\mathrm{Mn}^{2+}$. Assuming that the choice of current density during reduction of the manganese plated stainless steel did not shift the equilibrium position significantly, the reactions (3) and (4) would be expected only in a $\mathrm{pH}$ range between 5 and 7.5. Below pH 5 the reaction (5) is more likely to occur, whereas above $\mathrm{pH} 7.5$ the reactions would be far more complex. The reactions involved and their respective standard electrode potentials are:

$$
\mathrm{MnO}_{2}+\mathrm{H}^{+}+\mathrm{e}^{-} \rightarrow \mathrm{MnOOH} ; \quad E^{0}=1.189 \mathrm{~V}
$$

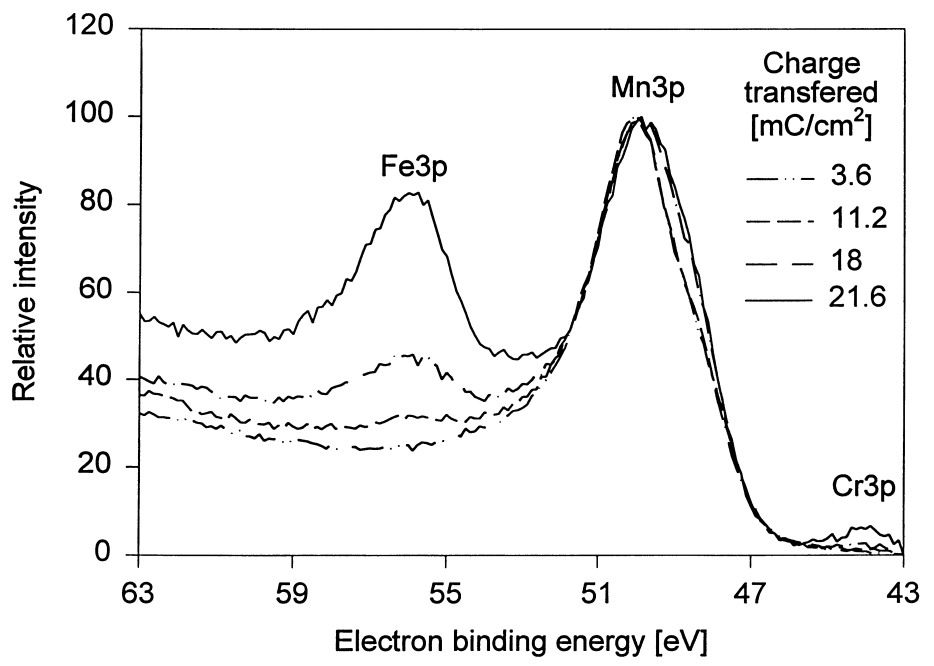

Fig. 6. XPS spectra of $\mathrm{Mn} 3 \mathrm{p}$ obtained from electrochemically reduced, $\mathrm{MnO}_{2}$ covered, $316 \mathrm{~L}$ stainless steel coupons. The spectra have been scaled arbitrarily so the height of the Mn3p equals 100 . 


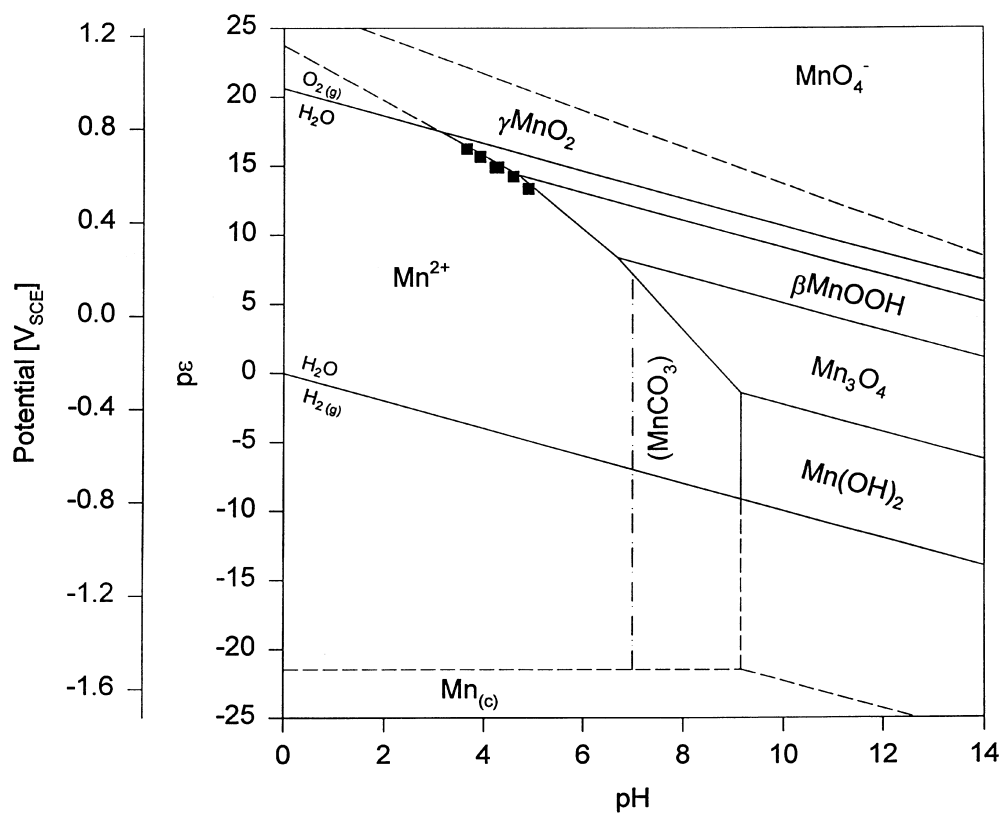

Fig. 7. Predominance diagram for an isolated manganese system. $\left[\mathrm{Mn}^{2+}\right]=1 \mathrm{mM}, T=25^{\circ} \mathrm{C}$. Dotted vertical line represents the equilibrium between $\mathrm{Mn}^{2+}$ and $\mathrm{MnCO}_{3}$ in an open system in contact with atmospheric air at 1 ATM. Squares indicate the results of our measurements, OCP of $316 \mathrm{~L}$ stainless steel corrosion electroplated with manganese dioxide.

$$
\begin{aligned}
& \mathrm{MnOOH}+3 H^{+}+\mathrm{e}^{-} \rightarrow \mathrm{Mn}^{2+}+2 \mathrm{H}_{2} \mathrm{O} ; \quad E^{0}=1.442 \mathrm{~V} \\
& \mathrm{MnO}_{2}+4 \mathrm{H}^{+}+2 \mathrm{e}^{-} \rightarrow \mathrm{Mn}^{2+}+2 \mathrm{H}_{2} \mathrm{O} ; \quad E^{0}=1.315 \mathrm{~V}
\end{aligned}
$$

In an open system, in equilibrium with atmospheric air, the presence of bicarbonates and the formation of $\mathrm{MnCO}_{3}$, reaction (6), will further complicate the manganese reactions.

$$
\mathrm{Mn}^{2+}+\mathrm{HCO}_{3}^{-} \rightarrow \mathrm{MnCO}_{3}+\mathrm{H}^{+}
$$

Assuming a concentration of $\mathrm{HCO}_{3}^{-}$equal to that in pure water, reaction (6) can be represented in the predominance diagram (Fig. 7) as a vertical line at $\mathrm{pH}$ 7. To

Table 5

Free energy of formation $\Delta \mathrm{G}_{\mathrm{f}}^{0}[\mathrm{~kJ} / \mathrm{mol}]$ for compounds used to prepare Fig. 7

\begin{tabular}{lllrll}
\hline$\alpha \mathrm{Mn}$ & 0 & $\mathrm{Mn}_{3} \mathrm{O}_{4}$ & -1283.20 & $\mathrm{H}_{2} \mathrm{CO}_{3}$ & -623.42 \\
$\mathrm{Mn}^{2+}$ & -228.10 & $\mathrm{Mn}(\mathrm{OH})_{2}$ & -615.00 & $\mathrm{HCO}_{3}^{-}$ & -587.06 \\
$\mathrm{MnO}_{2}$ & -465.14 & $\mathrm{MnO}_{4}^{-}$ & -477.20 & $\mathrm{CO}_{3}^{2-}$ & -527.90 \\
$\mathrm{MnOOH}$ & -563.2 & $\mathrm{MnCO}_{3}$ & -816.70 & $\mathrm{H}_{2} \mathrm{O}$ & -237.10 \\
\hline
\end{tabular}


calculate the equilibrium position we used a concentration of $\mathrm{HCO}_{3}^{-}$in an open system consisting of pure water in equilibrium with atmospheric air.

As seen in Fig. 6, the ratio of iron to manganese increased progressively during the oxide reduction, indicating that the manganese dioxide film thickness decreased. In addition, the amount of manganese detected in solution (Table 4) increased during the reduction. We concluded that the manganese dioxide was progressively removed from the surface through the overall reaction (5).

The curves in Fig. 6, showing Mn3p binding energies, develop a shoulder on the right side of the Mn3p peak as the reduction progresses. Such a shoulder often indicates the formation of a second peak superimposed on the initial peak, possibly due to the presence of another manganese compound. Using standard XPS peak fitting routines, the two peaks were deconvoluted, and the position of the second peak was determined to be between 49.0 and $49.3 \mathrm{eV}$. Based on the position of the Mn3p peak from the manganese standards (Table 3) we concluded that the newly accumulating compound was $\mathrm{MnOOH}$. Fig. 8 shows the development of the areas under the peaks as the function of time. As the $\mathrm{MnO}_{2}$ peak decreased, the $\mathrm{MnOOH}$ signal increased slightly, reached a maximum and declined by the end of the process of oxide reduction. Such behavior can be explained in terms of $\mathrm{MnOOH}$ being an intermediate product of the reaction. These observations corroborate our previous conclusions, that reaction (5) has an intermediate product: $\mathrm{MnO}_{2}$ is first reduced to $\mathrm{MnOOH}$, reaction (3), gaining one electron, then further into divalent manganese, $\mathrm{Mn}^{2+}$, reaction (4), gaining the second electron. Our findings are in good agreement with the thermodynamic properties of the manganese system. The free energy change for reaction (3), $\mathrm{MnO}_{2}$ reduction to $\mathrm{MnOOH}$, is $-58.1 \mathrm{~kJ} / \mathrm{mol}$ at $\mathrm{pH} 7$ and $1 \mu \mathrm{M} \mathrm{Mn}{ }^{2+}$. When $\mathrm{MnO}_{2}$ is reduced to other compounds than $\mathrm{MnOOH}$, the respective reactions yield

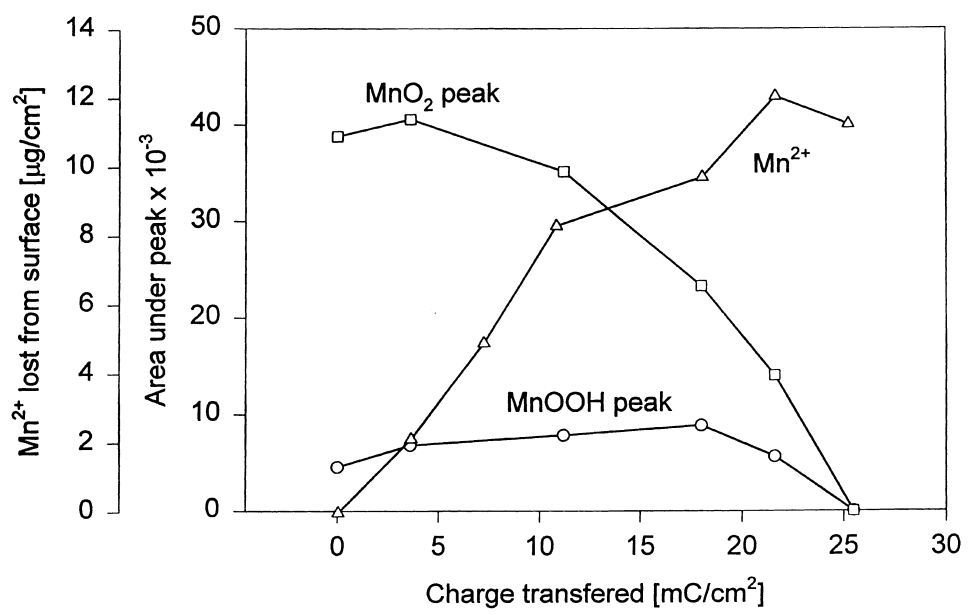

Fig. 8. Area under the $\mathrm{Mn3p}$ peak for $\mathrm{MnO}_{2}$ and for $\mathrm{MnOOH}$ determined from peak fitting the curves in Fig. 5 including manganese lost from the coupon surface as $\mathrm{Mn}^{2+}$ during reduction. 
lower amounts of free energy change per electron equivalent: $\mathrm{Mn}(\mathrm{OH})_{2}(-35.0 \mathrm{~kJ} /$ $\mathrm{mol}), \mathrm{Mn}^{2+}(-55.8 \mathrm{~kJ} / \mathrm{mol}), \mathrm{MnO}(-27.5 \mathrm{~kJ} / \mathrm{mol}), \mathrm{Mn}_{2} \mathrm{O}_{3}(-54.0 \mathrm{~kJ} / \mathrm{mol})$ and $\mathrm{Mn}_{3} \mathrm{O}_{4}(-50.5 \mathrm{~kJ} / \mathrm{mol})$.

There is a second possible explanation for the behavior seen in Fig. 7. Instead of being reduced electrochemically by accepting an electron from the metal surface, the manganese oxyhydroxide can disproportionate into divalent manganese and manganese dioxide, reaction (7).

$$
\mathrm{MnOOH}+\mathrm{H}^{+} \rightarrow \frac{1}{2} \mathrm{MnO}_{2}+\frac{1}{2} \mathrm{Mn}^{2+}+\mathrm{H}_{2} \mathrm{O}
$$

However, the free energy change at $\mathrm{pH} 7$ and $1 \mu \mathrm{M} \mathrm{Mn}{ }^{2+}$ is $+32.6 \mathrm{~kJ} / \mathrm{mol}$ for reaction (7) compared to $-53.5 \mathrm{~kJ} / \mathrm{mol}$ for reaction (4). Thus, the probability of reaction (4) happening is far greater than the probability of any other reaction, including reaction (7).

If reactions (3) and (4) take place within a biofilm containing MOB, the divalent manganese, $\mathrm{Mn}^{2+}$, produced by the electrochemical reaction of microbially deposited manganese dioxide, reaction (4), will be available to the $\mathrm{MOB}$, and may be oxidized again to $\mathrm{MnO}_{2}$. Thus, the cathodic reactions (3) and (4) are able to perpetually consume electrons from anodic (corrosion) reactions at different sites at the metal surface, as long as the MOB continue to deposit manganese dioxide.

The electrochemical reduction of manganese dioxide may be a part of the natural cycle of manganese [30-32], in which both oxidation and reduction of manganese compounds are carried out by a variety of microorganisms. Fig. 9 shows such hypothetical arrangements when the electrochemical reactions (3) and (4) are combined with the natural cycle of manganese. Because some microorganisms reduce manganese oxides to gain energy, the reduction of manganese dioxide in the cycle is shown as a competition between the biological (dashed line) and the electrochemical pathway. Whether or not the biological reduction is significant depends upon the bacterial composition of the biofilm, especially near the metal substratum. The effect of manganese dioxide on the

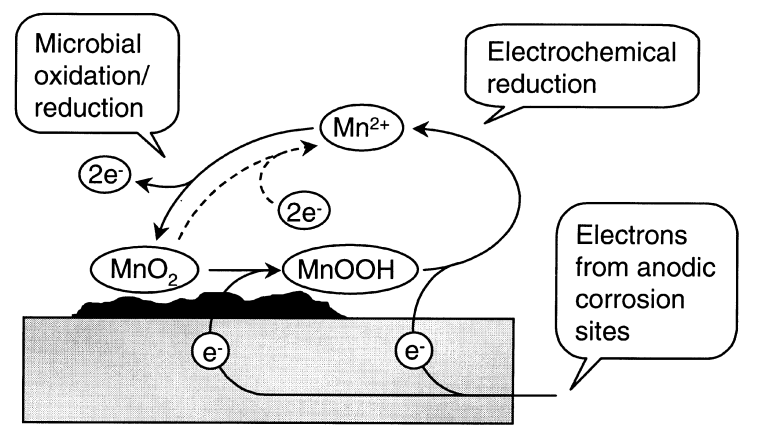

Fig. 9. Manganese cycling at a stainless steel surface providing the cathodic reaction in corrosion process. 
corrosion of metals may also depend on the nature of the anodic reaction responsible for the dissolution of the metal. Electrically connected to sites with SRB activity, known to be potentially corrosive to e.g. stainless steels [15,33,34], the presence of manganese dioxide may increase the corrosion rate by providing an efficient cathodic reaction. Our observations agree well with the notion that whenever biofilms accumulate on cathodic members of galvanic couples, a significant increase in the reduction current can be expected [35].

\section{Conclusion}

- Biomineralized manganese, deposited by the Manganese Oxidizing Bacteria, $L$. discophora SP-6, grown on 316L stainless steel corrosion coupons under laboratory conditions, consisted of manganese dioxide, $\mathrm{MnO}_{2}$.

- Natural biofilms grown under field conditions contained a wide variety of manganese minerals. Thus, other not yet fully understood parameters, presumably of microbial nature, complicate the clear image of microbial manganese deposition we get from laboratory studies.

- Manganese dioxide, plated on stainless steel corrosion coupons, was reduced electrochemically to divalent manganese, $\mathrm{Mn}^{2+}$, obtaining two electrons from the metal substratum. Manganese oxyhydroxide, $\mathrm{MnOOH}$, was determined as an intermediate product in this reaction.

- The presence of biomineralized manganese dioxide as a cathodic reactant may increase the corrosion rate and/or the probability of active corrosion. The Manganese Oxidizing Bacteria, active in the process of manganese dioxide biomineralization, may hypothetically use the product of $\mathrm{MnO}_{2}$ reduction, $\mathrm{Mn}^{2+}$, making the cycle perpetual.

\section{Acknowledgements}

This work was supported by the Faculty of Engineering and Science, Aalborg University, Denmark, the United States Office of Naval Research under the AASERT program, contract number N00014-92-J-1966, under ONR contract number N00014-95-1-0900, and by Cooperative Agreement EEC-8907039 between the National Science Foundation and Montana State University, Bozeman, MT, USA.

\section{References}

[1] A. Mollica, A. Trevis, Correlation Entre la Formation de la Pellicule Primaire et la Modification de la Cathodique sur des Aciers Inoxydables Expérimentés en eau de Mer aux Vitesses de 0,3 A 
$5,2 \mathrm{~m} / \mathrm{s}$, in: Proceedings of Fourth International Congress Marine Corrosion and Fouling, JuanLes-Pins, Antibes, France, 1976.

[2] R. Johnsen, E. Bardal, Corrosion 41 (5) (1985) 296.

[3] S.C. Dexter, G.Y. Gao, Corrosion 44 (10) (1988) 717.

[4] S. Motoda, Y. Suzuki, T. Shinohara, Corrosion Sci. 31 (1990) 515.

[5] M. Eashwar, S. Maruthamuthu, S. Sathiyanarayanan, K. Balakrishnan, Corrosion Sci. 37 (8) (1995) 1169.

[6] V. Scotto, R. Di Cintio, G. Marcenaro, Corrosion Sci. 25 (3) (1985) 185.

[7] R. Holthe, E. Bardal, P.O. Gartland, Proceedings of Corrosion 1988, Paper No. 398, Houston, TX, NACE, 1988.

[8] B. Little, P. Wagner, F. Mansfeld, Int. Mat. Rev. 36 (6) (1991) 253.

[9] M. Eashwar, S. Maruthamuthu, Biofouling 8 (1995) 203.

[10] S. Dexter, S-H. Lin, Proceedings of Seventh International Congress on Marine Corrosion and Fouling, Valencia, Spain, 1988.

[11] P. Chandrasekaran, S.C. Dexter, Proceedings of Corrosion 1993, Paper No. 493, Houston, TX, NACE, 1993.

[12] P. Linhardt, Failure of chromium-nickel steel in a hydroelectric power plant by manganese-oxidizing bacteria, in: E. Heitz, H-C. Flemming, W. Sand (Eds.), Microbially Influenced Corrosion of Materials, Springer Berlin Heidelberg, 1996, pp. 221-230.

[13] P. Linhardt, Werkstoffe und Korrosion 45 (1994) 79.

[14] W.H. Dickinson, F. Caccavo Jr, Z. Lewandowski, Corrosion Sci. 38 (8) (1996) 1407.

[15] W.H. Dickinson, Z. Lewandowski, Biofouling 10 (13) (1996) 79.

[16] W.H. Dickinson, F. Caccavo Jr, B.H. Olesen, Z. Lewandowski, Appl. Env. Microbiol. 63 (7) (1996) 2502

[17] L.F. Adams, W.C. Ghiorse, Geochim. Cosmochim. Acta 52 (1988) 2073.

[18] D. Emerson, W.C. Ghiorse, Appl. Env. Microbiol. 58 (12) (1992) 4001.

[19] R.L. Gherna, in: P. Gerhardt (Ed.), Manual of Methods for General Microbiology, American Society for Microbiology, Washington, 1981.

[20] P. Brewer, D. Spencer, Limnol. Oceanogr. 16 (1971) 107.

[21] J.F. Moulder, W.F. Stickle, P.E. Sobol, K.D. Bowler, Handbook of X-ray Photoelectron Spectroscopy - A Reference Book of Standard Spectra for Identification and Interpretation of XPS Data, Perkin-Elmer Corporation, Minnesota, 1992.

[22] M. Oku, K. Hirokawa, J. Electron Spec. Rel. Phen. 7 (1975) 465.

[23] M. Oku, K. Hirokawa, J. Electron Spec. Rel. Phen. 8 (1976) 475.

[24] G. Fierro, G.M. Ingo, F. Mancia, L. Scoppio, N. Zacchetti, J. Mat. Sci. 25 (1990) 1407.

[25] A.J. Swift, Mikrochim. Acta 120 (1995) 149.

[26] J. Pendyala, Chemical effects of biofilm colonisation of stainless steels, PhD thesis, Montana State University, Bozeman, MT (1996).

[27] R. Giovanoli, U. Leuenberger, Helv. Chim. Acta 52 (1969) 2333.

[28] C.A. Johnson, A.G. Xyla, Geochim. Cosmochim. Acta 52 (1991) 2861.

[29] A.J. Bard, R. Parson, J. Jordan, Standard Potentials in Aquatic Solutions, Marcel Dekker, Inc, New York, 1985

[30] A.C. Greene, J.C. Madgwick, Appl. Env. Microbiol. 57 (1991) 1114.

[31] D.R. Lovley, Advances in Agronomy 54 (1995) 175.

[32] K.H. Nealson, B.M. Tebo, R.A. Rosson, Adv. Appl. Microbiol. 33 (1988) 279.

[33] V.K. Gouda, H.M. Shalaby, I.M. Banat, Corrosion Sci. 35 (1993) 683.

[34] A. Pourbaix, L.E. Aguiar, A-M. Clarinval, Corrosion Sci. 35 (1993) 693.

[35] S.C. Dexter, J.P. Lafontaine, Corrosion 54 (1998) 851. 